\title{
Fragaria virginiana resists tarnished plant bug
}

\author{
Adam Dale $^{1 *}$, Dragan Galic ${ }^{1} \&$ Rebecca H. Hallett ${ }^{2}$ \\ ${ }^{1}$ Department of Plant Agriculture, University of Guelph, Box 587, Simcoe, ON, Canada N3Y 4N5, \\ ${ }^{2}$ Department of Environmental Biology, University of Guelph, Guelph, ON, Canada N1G 2W1
}

Accepted: 29 October 2007

Key words: Lygus lineolaris, strawberry, resistance, Heteroptera, Miridae, dayneutral variety

\begin{abstract}
An experiment that involved 79 named cultivars and advanced selections of Fragaria $\times$ ananassa L., 46 Fragaria virginiana Duch. clones, and 12 F. virginiana backcross selections, and eight Fragaria virginiana $\times$ Fragaria chiloensis (L.) Duch. (all Rosaceae) selections, was conducted to detect variation in strawberry genotypes for resistance to tarnished plant bug, Lygus lineolaris (Palisot de Beauvois) (Heteroptera: Miridae). The F. virginiana genotypes were shown to be more resistant than the cultivars and advanced selections in both 2001 and 2002. Within the group of cultivars and advanced selections, several June-bearing and dayneutral genotypes were more resistant than others. There were fewer plant bugs on F. virginiana than on the cultivars and hybrids. Insect numbers were consistently correlated with percentage of damaged fruits and damage severity, but total numbers of flowers and fruits were only correlated with insect numbers, percentage fruit damage, and damage severity in 1 of the 2 years. Our results suggest that strawberry cultivars, highly resistant to tarnished plant bug, can be bred, if the trait is introgressed from F. virginiana selections.
\end{abstract}

\section{Introduction}

The tarnished plant bug, Lygus lineolaris (Palisot de Beauvois) (Heteroptera: Miridae), is one of two major pests of June-bearing strawberries, Fragaria $\times$ ananassa L. (Rosaceae), in Ontario, Canada (Dale et al., 2000). Nymphs and adults feed on flowers and fruits and cause the developing fruits to become deformed and unmarketable (Schaefers, 1980; Handley \& Pollard, 1993). The amount of damage can vary from year to year depending on plant bug feeding pressure (Schaefers, 1980; Handley et al., 1996).

At present, the only effective way to control the insect is to apply pesticides. However, several strategies, used alone or together, can potentially control tarnished plant bug, including vacuuming (Vincent \& Lachance, 1993; Rancourt et al., 2003), trap crops (Easterbrook \& Tooley, 1999; Brown, 2004), reflective mulch (Rhainds et al., 2001), parasitoids and predators (Udayagiri et al., 2000; Tilmon \& Hoffmann, 2003), and resistant or tolerant varieties (Handley et al., 1991). In June-bearing varieties, early varieties often do not have tarnished plant bug injury as they flower before the insects appear (Mass, 1984).

Dayneutral strawberry varieties were first introduced in 1980 (Bringhurst \& Voth, 1980), and have the potential to

*Correspondence: E-mail: adale@uoguelph.ca expand the harvest season from 1 to 3 or more months each year throughout northern North America, as they flower and fruit from late July until the end of September (Pritts \& Dale, 1989). In the early 1980s, four northernadapted dayneutral varieties were released (Draper et al., 1981; Anon, 1997; Okie, 1999). No new northern adapted dayneutral varieties have been released since that time, although a series of dayneutral varieties have been released from California.

The major drawback of dayneutral strawberries is that they can be severely damaged by tarnished plant bug. These insects reach their maximum populations during the main summer harvest of dayneutrals (Bostanian, 1994) and can extensively damage the fruit. Because the dayneutral strawberry produces flowers and fruits more or less continually, tarnished plant bug cannot be controlled with currently available pesticides as their days-to-harvest requirements are longer than the harvest intervals.

Strawberries can be bred to resist or tolerate tarnished plant bugs, but little research has been done in this area. Handley et al. (1991) showed that there was considerable variation among 20 June-bearing strawberry cultivars for tarnished plant bug injury. Over 2 years, susceptible varieties, such as 'Kent' and 'Micmac', were damaged over twice as much as tolerant varieties, such as 'Honeoye' and 'Sparkle', and five of the six most tolerant cultivars were closely related. These results have been confirmed in Maine 
(Handley \& Pollard, 1993) and in Wisconsin in 1999 (B Smith, pers. comm.). In an Ontario study that compared two dayneutral strawberries, Tristar had significantly less damaged fruit than Tribute (A Dale, unpubl.). Thus, there is evidence to suggest that strawberry is variable for resistance to tarnished plant bug and that breeding for the trait should be possible.

The objective of this work was to determine the range of varietal susceptibility to tarnished plant bug in cultivated and wild strawberries, so that suitable parents could be selected for further breeding. A preliminary report of this research indicated that Fragaria virginiana Duch. genotypes were more tolerant of tarnished plant bug than other Fragaria genotypes (Dale et al., 2003).

\section{Materials and methods}

Two hundred strawberry genotypes were planted in late May 2001 at the Simcoe Research Station of the University of Guelph, Simcoe, Ontario, Canada. This late planting time enabled early flowering genotypes to be subjected to normal tarnished plant bug populations. Genotypes were from three origins: 52 named cultivars and 43 advanced selections of Fragaria $\times$ ananassa; 65 F. virginiana clones; and $F$. virginiana hybrids, including $25 F$. virginiana backcross selections and 15 F. virginiana $\times$ F. chiloensis (L.) Duch. selections. Sixteen cultivars and advanced selections were dayneutral, as were six of the F. virginiana backcross selections and six of the $F$. virginiana clones.

All plants, either as cold-stored bare root plants or greenhouse grown plug plants, were planted in a randomized complete block design with 12 replicates of single plant plots of each genotype. The 12 replicates were placed on six raised beds with two replicates per bed. Plants were planted in a Wilsonville gravely sandy till soil in two staggered rows, with $20 \mathrm{~cm}$ within and between the rows, on raised beds $1.5 \mathrm{~m}$ apart, covered with black plastic, and trickle irrigated. No pesticides were applied to the experiment and the plants were fertilized according to Ontario recommendations (Ontario Ministry of Agriculture and Food, 2001). Selections that were missing or plants that had died were replaced in September 2001.

In order to determine whether tarnished plant bug nymphs caused flowers to abort, in 2002 the first two replicates were sprayed weekly with Thiodan $50 \mathrm{WP}$ (active ingredient endosulfan 50\%; Bayer CropScience, Calgary, Alberta, Canada) at $4 \mathrm{~kg} \mathrm{ha}^{-1}$ to kill any nymphs using a shielded hand sprayer, and the number of fruits and flowers per plant were counted weekly. An aborted flower was considered as one in which the receptacle did not swell. Severe frosts on the nights of 20-22 May 2002 killed many flowers.
All fruit were rated weekly from 3 July to 11 October 2001 and from 11 June to 21 October 2002 for tarnished plant bug damage on a 1-4 scale. Damage from tarnished plant bug was considered to be present when large, apparently fully grown, achenes were clustered together. For 1 , severe damage, large achenes were clustered together with less than about $10 \%$ of normal ripe fruit tissue present; 2 , apical seediness where large achenes were clustered at tip of fruit; 3, slight damage where large achenes were clustered irregularly in one or two small areas of the fruit; and 4 , no damage. The number of flowers that did not produce fruit was also counted. All fruit and flowers that did not produce fruit were removed once they were rated. Because many of the F. virginiana genotypes had small fruits $(<1 \mathrm{~g})$, it was impossible to distinguish slightly damaged fruit from undamaged ones, so these were rated as 1,2, or 4 .

The tarnished plant bug population was monitored weekly by counting the number of nymphs and adults on a single flowering inflorescence of each flowering plant in half the replicates, which were randomly selected on each sampling date. Nymphs and adults were tapped onto a plate from a single inflorescence taken at random from within the plant and counted. Adult tarnished plant bugs were monitored with 10 white sticky traps $(22.5 \times 27.5 \mathrm{~cm})$ (Great Lakes IPM, Vestaburg, MI, USA), with one trap placed in each of 10 randomly selected replicates. Sticky traps were placed at a height of $30 \mathrm{~cm}$ and were replaced weekly.

Data from all flowers and fruits were analysed by analysis of variance for percentage of damaged fruit, damage severity, the total number of flowers, total number of fruits, and percentage of flowers that did not produce fruit using PROC MIXED (SAS version 8.2, 1999; SAS Institute, Cary, $\mathrm{NC}, \mathrm{USA}$ ). As there were many damaged fruit values below $10 \%$, data were normalized by angular transformation $(\mathrm{Y}=$ arcsine $\sqrt{x+0.01})$. The percentage of damaged fruit was calculated as the number of fruit in categories 1,2 , and 3 as a percentage of the total number of fruit; damage severity was calculated as the sum of $[(1 \times$ category 4$)$ $+(2 \times$ category 3$)+(3 \times$ category 2$)+(4 \times$ category 1$)]$ divided by the total number of fruit. The total number of fruits was calculated as the sum of fruits in categories 1-4, and the total number of flowers as the sum of the total number of fruits and the number of flowers. The number of aborted flowers was expressed as a percentage of the total number of flowers. Any selection that flowered in fewer than four replicates or had a total of fewer than 15 flowers was omitted from analyses in 2001, and fewer than four replicates and an average of fewer than five flowers per plant in 2002. This reduced the number of genotypes for further analysis to 145 . Also, the two replicates that were sprayed with Thiodan in 2002 were excluded from the analyses for damaged fruit and damage severity. 
Figure 1 The number of tarnished plant bug, Lygus lineolaris, nymphs and adults found per 100 inflorescences sampled, and the number of adults caught on 10 white sticky traps in 200 strawberry, Fragaria spp., genotypes sampled weekly in (A) 2001 and (B) 2002.
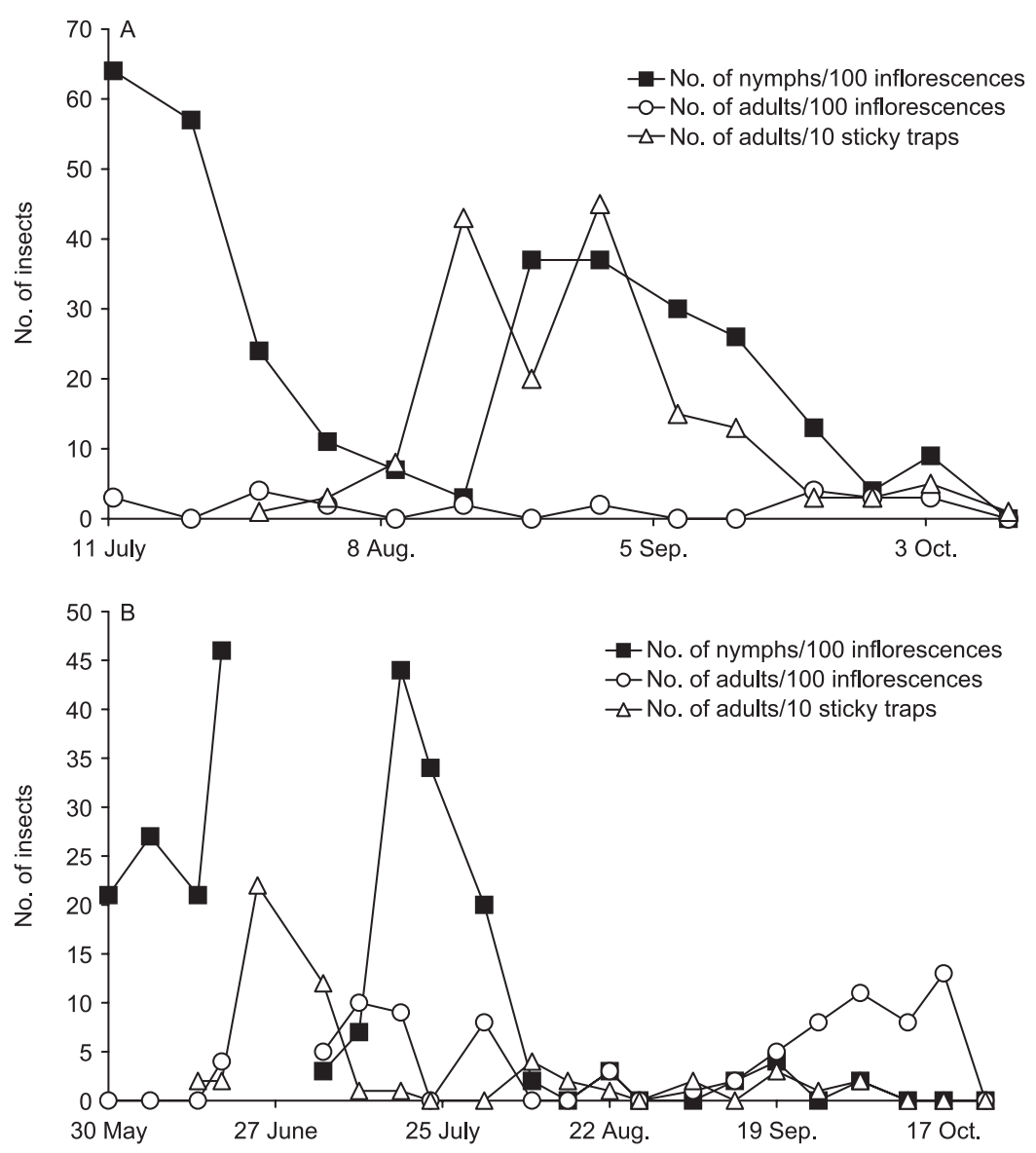

For analysis of data from both years, only those genotypes present in both years and that satisfied the above requirements were included in analyses. In the PROC MIXED model, the three origin groups (cultivars and selections, hybrids with F. virginiana, and F. virginiana), genotypes within their origins, and the year effect were treated as fixed effects and replicates as a random effect. Where data were transformed for analysis, detransformed means are presented. The least significant differences for the origin ${ }^{\star}$ year interaction were calculated using the error mean square from analyses of variance using PROC GLM. Correlations were done between cultivar means for mean number of insects per inflorescence, percentage of damaged fruit, and damage severity using PROC PRINCOMP. For the insect populations, the mean number of nymphs and adults per inflorescence, and the total number of adults on 10 sticky traps were calculated for each sampling date.

In 2002, the percentage of aborted flowers was used to analyse whether tarnished plant bugs caused flowers to abort. The sprayed and unsprayed plots were used as the fixed effect in an unbalanced analysis of variance using PROC MIXED.

\section{Results}

Tarnished plant bugs were present throughout the flowering and fruiting period in both years. In 2001, there were two generations of nymphs, in July and mid-August through September, and an August population of adults, which appeared 1-2 weeks before the second generation of nymphs (Figure 1). In 2002, there were two generations of nymphs, in June and July, with only low numbers thereafter. Two generations of adults were seen in 2002, one late June to early July and the other mid-September to October.

Tarnished plant bug damage to fruits ranged from $<1$ to $75 \%$ in both years for the individual genotypes (data not shown). Analysis of the percentage of damaged fruits for both years revealed statistically significant differences for the main effects of origin and genotype, but not between years (Table 1). Significant origin by year and genotype $e^{\star}$ year interactions were observed. The F. virginiana genotypes were less damaged than the cultivars and selections, and damage to the hybrids was intermediate between the other two groups (Table 2 ). The origin ${ }^{\star}$ year interaction arose 
Table 1 Variance ratios (F-ratios) and significance levels (P) for percentage of Fragaria spp. fruit damaged by tarnished plant bug, Lygus lineolaris, damage severity, number of insects (i.e., number of tarnished plant bug nymphs and adults) per inflorescence, and total numbers of fruit per plant and flowers per plant for genotypes examined in Simcoe, Ontario, Canada, 2001 and 2002

\begin{tabular}{|c|c|c|c|c|c|c|c|c|c|c|c|}
\hline & \multirow[b]{2}{*}{ d.f. } & \multicolumn{2}{|c|}{$\begin{array}{l}\text { Percentage of } \\
\text { fruit damaged }^{1}\end{array}$} & \multicolumn{2}{|c|}{ Damage score } & \multicolumn{2}{|c|}{$\begin{array}{l}\text { Number of insects } \\
\text { per inflorescence }\end{array}$} & \multicolumn{2}{|c|}{$\begin{array}{l}\text { Total number } \\
\text { of flowers }\end{array}$} & \multicolumn{2}{|c|}{$\begin{array}{l}\text { Total number } \\
\text { of fruits }\end{array}$} \\
\hline & & $\begin{array}{l}\text { Variance } \\
\text { ratio }\end{array}$ & $\mathrm{P}$ & $\begin{array}{l}\text { Variance } \\
\text { ratio }\end{array}$ & $\mathrm{P}$ & $\begin{array}{l}\text { Variance } \\
\text { ratio }\end{array}$ & $\mathrm{P}$ & $\begin{array}{l}\text { Variance } \\
\text { ratio }\end{array}$ & $\mathrm{P}$ & $\begin{array}{l}\text { Variance } \\
\text { ratio }\end{array}$ & $\mathrm{P}$ \\
\hline Origin & 2 & 155.0 & $<0.0001$ & 95.7 & $<0.0001$ & 9.9 & $<0.0001$ & 185.6 & $<0.0001$ & 86.9 & $<0.0001$ \\
\hline Genotype (origin) & 143 & 3.6 & $<0.0001$ & 3.6 & $<0.0001$ & 2.9 & $<0.0001$ & 7.7 & $<0.0001$ & 8.3 & $<0.0001$ \\
\hline Year & 1 & 0.03 & 0.86 & 5.7 & 0.17 & 137.5 & $<0.0001$ & 1352.7 & $<0.0001$ & 699.4 & $<0.0001$ \\
\hline Origin $^{\star}$ year & 2 & 22.8 & $<0.0001$ & 24.4 & $<0.0001$ & 3.4 & 0.032 & 147.5 & $<0.0001$ & 60.5 & $<0.0001$ \\
\hline Genotype (origin)*year & 143 & 2.1 & $<0.0001$ & 1.8 & $<0.0001$ & 2.4 & $<0.0001$ & 6.0 & $<0.0001$ & 6.3 & $<0.0001$ \\
\hline
\end{tabular}

${ }^{1}$ Data transformed using angular transformation.

because the hybrids were less damaged and the cultivars more damaged in 2002 than in 2001. In 2001, the range of percentage damaged fruits was slightly narrower for F. virginiana genotypes and the hybrids than for the cultivars and selections. In that year, $80 \%$ of $F$. virginiana genotypes, $70 \%$ of the hybrids, and $48 \%$ of the cultivars had $15 \%$ or less of fruit damaged (Figure 2). In 2002, the ranges for $F$. virginiana genotypes and the hybrids were narrower than that for the cultivars and selections, and all the F. virginiana genotypes, $85 \%$ of hybrids, and $20 \%$ of cultivars had $15 \%$ or less of fruit damaged (Figure 2).

The percentage of damage to fruits of individual genotypes in both years were correlated $(\mathrm{r}=0.371, \mathrm{P}=0.001$; $n=144$ ). A number of genotypes had low levels of fruit damage in both years: in the cultivars and selections, Evangeline (9\% in 2001, 18\% in 2002); in the hybrids, FV4-90 (5 and 5\%) and FV148-5 (8 and 11\%); and in the F. virginiana genotypes, Eagle 2 ( 1 and $4 \%$ ), Normandale 2 (7 and 4\%), Eagle 6 (9 and 3\%), and Eagle 16 (10 and
9\%). Honeoye, which is considered to be tolerant to tarnished plant bug (Handley et al., 1991), had 12\% damage in 2001 and 39\% in 2002.

Among dayneutral cultivars, Fort Laramie (12 and 8\%) had the lowest percentage of damaged fruit in both years, and Fern (22 and 15\%), Tribute (27 and 15\%), and Tristar (36 and 9\%) had low damage levels in 2002. The dayneutral $F$. virginiana genotypes, Black Sturgeon River 11, 13, and 24 ( 3 and $3 \%, 1$ and $7 \%$, and 11 and $4 \%$, respectively) had less damage than Fort Laramie.

Analysis of damage severity scores for both years revealed statistically significant differences for the main effects of origin, and genotype but not year (Table 1). Significant origin $^{*}$ year and genotype ${ }^{*}$ year interactions arose because in 2002, but not 2001, the F. virginiana genotypes and hybrids had a lower score than the cultivars (Table 2).

Analysis of the number of insects per inflorescence in both years revealed that the main effects of origin, genotype, and year, and the genotype ${ }^{*}$ year interaction differed

Table 2 The mean number of tarnished plant bug, Lygus lineolaris, nymphs and adults per 100 Fragaria spp. inflorescences, detransformed mean percentage of fruit damaged, and mean score for damage severity by tarnished plant bug nymphs for three origins of genotypes tested in 2001 and 2002. Transformed means are given in brackets

\begin{tabular}{|c|c|c|c|c|c|c|c|c|c|c|}
\hline \multirow[b]{2}{*}{ Origin } & \multirow{2}{*}{$\begin{array}{l}\text { Number of } \\
\text { genotypes }\end{array}$} & \multicolumn{3}{|c|}{ Percentage of fruit damaged ${ }^{1}$} & \multicolumn{3}{|c|}{ Damage score $^{2}$} & \multicolumn{3}{|c|}{$\begin{array}{l}\text { Number of insects } \\
\text { per inflorescence }\end{array}$} \\
\hline & & 2001 & 2002 & Mean & 2001 & 2002 & Mean & 2001 & 2002 & Mean \\
\hline Cultivars & 79 & $16.9(0.425)$ & $27.3(0.551)$ & $21.9(0.488)$ & 1.37 & 1.47 & 1.42 & 0.835 & 0.354 & 0.594 \\
\hline Hybrids & 20 & $12.1(0.356)$ & $6.9(0.267)$ & $9.3(0.312)$ & 1.31 & 1.17 & 1.24 & 1.098 & 0.346 & 0.722 \\
\hline F. virginiana & 46 & $5.9(0.247)$ & $4.4(0.215)$ & $5.1(0.231)$ & 1.22 & 1.13 & 1.17 & 0.592 & 0.177 & 0.384 \\
\hline Mean & & $11.2(0.343)$ & $11.3(0.344)$ & & 1.30 & 1.26 & & 0.841 & 0.292 & \\
\hline
\end{tabular}

${ }^{1}$ Least significant difference $(\mathrm{LSD})(\mathrm{P}=0.05)$ for year ${ }^{\star}$ origin (transformed) $=0.051$.

${ }^{2} \operatorname{LSD}(\mathrm{P}=0.05)$ for year ${ }^{\star}$ origin $=0.06$.

${ }^{3} \operatorname{LSD}(\mathrm{P}=0.05)$ for year ${ }^{\star}$ origin $=0.36$ 

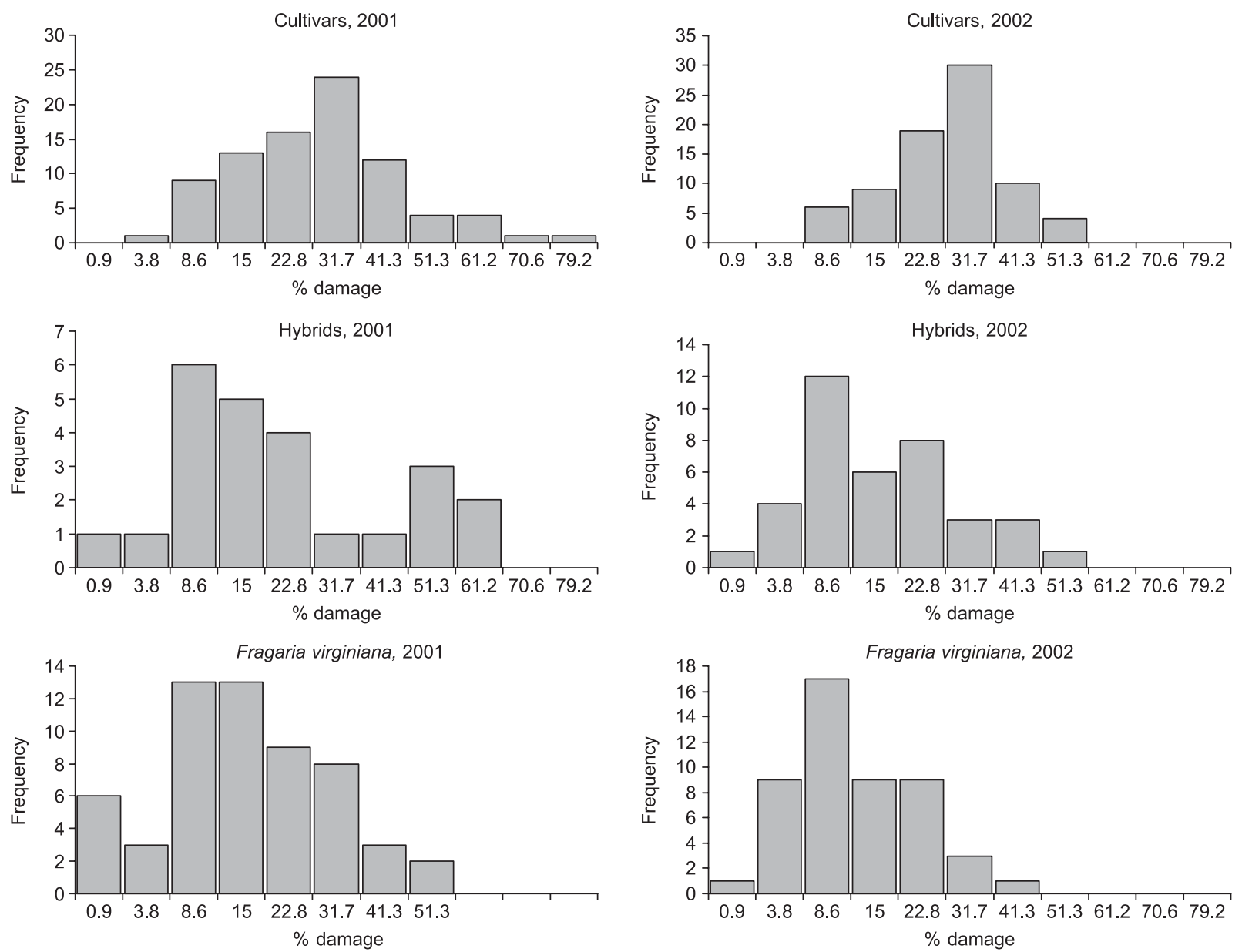

Figure 2 Frequency histograms of the mean percentage of fruit damaged by tarnished plant bug, Lygus lineolaris, for strawberry, Fragaria spp., genotypes from three origins tested in 2001 and 2002. The range groupings for the percentage of fruit damaged are based on 0.1 radians of the angular transformation of the original data. The values given are the untransformed values for the 0.1 radian intervals given as percentages.

significantly (Table 1 ). The F. virginiana genotypes supported fewer insects than did the hybrids and cultivars and there were fewer insects in 2002 than in 2001 (Table 2).

For both the total number of flowers and total number of fruits, all the main effects and interactions differed significantly (Table 1 ). There were five times as many flowers and almost four times more fruits in 2002 than in 2001 (Table 3) as the plants had grown much larger by 2002. The F. virginiana genotypes had more flowers and fruits than the cultivars and selections, and the hybrids were intermediate between the other two groups (Table 3).

The number of insects was significantly correlated with the percentage of damaged fruit and the damage score in both years (Table 4). The percentage of damaged fruit and the damage score were very highly correlated in both years. In 2001, total numbers of flowers and fruits were correlated with number of insects, but not with percentage of damaged fruits or damage score. In 2002, total numbers of flowers and fruits were negatively correlated with percentage of damaged fruits and damage scores, and were not correlated with number of insects. In 2002, the percentage of aborted flowers did not differ significantly between the sprayed and unsprayed treatments (51.3 and $52.0 \%, \mathrm{P}=0.90$, for sprayed and unsprayed plots, respectively).

\section{Discussion}

In this study, the F. virginiana genotypes were more resistant than the cultivated strawberry genotypes and the full range of variability was found in their hybrids. This result confirms the variability found in cultivated strawberry cultivars previously reported (Handley et al., 
Table 3 The mean total number of Fragaria spp. flowers and mean total number of fruits per plant for the three origins of genotypes tested in 2001 and 2002

\begin{tabular}{|c|c|c|c|c|c|c|c|}
\hline \multirow[b]{2}{*}{ Origin } & \multirow{2}{*}{$\begin{array}{l}\text { Number of } \\
\text { genotypes }\end{array}$} & \multicolumn{3}{|c|}{ Total number of flowers per plant ${ }^{1}$} & \multicolumn{3}{|c|}{ Total number of fruits per plant ${ }^{2}$} \\
\hline & & 2001 & 2002 & Mean & 2001 & 2002 & Mean \\
\hline Cultivars & 79 & 13.2 & 51.1 & 32.2 & 5.9 & 19.1 & 12.5 \\
\hline Hybrids & 20 & 19.1 & 117.0 & 68.1 & 6.7 & 30.4 & 18.5 \\
\hline F. virginiana & 46 & 26.5 & 129.6 & 78.0 & 10.9 & 41.7 & 26.3 \\
\hline Mean & & 19.6 & 99.2 & & 7.8 & 30.4 & \\
\hline
\end{tabular}

${ }^{1}$ Least significant difference $(\mathrm{LSD})(\mathrm{P}=0.05)$ for year ${ }^{*}$ origin $=3.5$.

${ }^{2} \mathrm{LSD}(\mathrm{P}=0.05)$ for year ${ }^{\star}$ origin $=7.0$.

1991; Easterbrook \& Simpson, 2000; Rhainds et al., 2001), but is the first report of greater resistance in F. virginiana than in cultivated strawberry. The category of resistance, that is, tolerance, antixenosis, or antibiosis, has not yet been determined (Painter, 1951; Kogan \& Ortman, 1987).

Morphological characteristics may influence oviposition and/or feeding preferences of tarnished plant bugs. The F. virginiana genotypes have more flowers and smaller fruits than cultivated strawberries, so fruit size or receptacle number could play a role in feeding preference of the bugs. For example, in a caged study with high numbers of adults per plant (Rhainds \& English-Loeb, 2003a), female plant bugs laid relatively more eggs per plant, but fewer eggs per receptacle, with increasing density of flowers per plant.

Our results suggest that tarnished plant bug populations do not grow in direct proportion to receptacle availability, so that tarnished plant bug numbers per inflorescence may be diluted when receptacles are abundant. Here, the number of insects was correlated with the number of flowers and fruit when receptacles were relatively less abundant (2001), but not when receptacles were more abundant (2002).

The differences found between genotypes for tarnished plant bug damage represent an intrinsic difference between the cultivars and F. virginiana. We did not find a consistent relationship between the abundance of receptacles and fruit damage, yet, percentage of damaged fruits and damage severity were consistent between years. Although a saturating functional response may occur when receptacle density is high (Rhainds \& English-Loeb, 2003b), we saw the same variability in damage among genotypes whatever the receptacle density, which is indicative of a resistance mechanism in F. virginiana.

From an evolutionary point of view, our data are consistent with tarnished plant bugs exerting a strong natural selection pressure on F. virginiana. The more susceptible a F. virginiana genotype is, the greater the chance that the seeds will be damaged and its reproductive capacity reduced. This level of selection pressure does not necessarily occur in breeding programmes where pesticides are often used to control tarnished plant bugs.

The mechanism of resistance to tarnished plant bug in F. virginiana is still not understood and requires investigation. There could be a compound in the ovaries that has an antixenotic or antibiotic effect on the plant bugs. This hypothesis fits with the observation of Easterbrook \& Simpson (2000) that there were significant differences between the weights of nymphs reared on three different cultivars. Dearomatized isophenylated phloroglucinols

Table 4 Correlation matrix (r-values) of Fragaria spp. genotype means for percent damage, damage score, number of Lygus lineolaris per inflorescence, total number of fruits, and total number of flowers for tarnished plant bug on genotypes $(\mathrm{n}=144)$ in 2001 and 2002

\begin{tabular}{|c|c|c|c|c|c|}
\hline & Year & Number of flowers & Number of fruits & Number of insects & Damage score \\
\hline \multirow[t]{2}{*}{ Percent damage } & 2001 & $0.12 \mathrm{~ns}$ & $0.14 \mathrm{~ns}$ & $0.38^{\star * *}$ & $0.96^{* * *}$ \\
\hline & 2002 & $-0.43^{\star * *}$ & $-0.30^{\star * *}$ & $0.33^{\star * *}$ & $0.97^{\star * *}$ \\
\hline \multirow[t]{2}{*}{ Damage score } & 2001 & $0.09 \mathrm{~ns}$ & $0.10 \mathrm{~ns}$ & $0.34^{\star * *}$ & \\
\hline & 2002 & $-0.46^{* * *}$ & $-0.35^{\star * *}$ & $0.26^{* * *}$ & \\
\hline \multirow[t]{2}{*}{ Number of insects } & 2001 & $0.45^{\star * *}$ & $0.42^{\star * *}$ & & \\
\hline & 2002 & $0.15 \mathrm{~ns}$ & $0.18 \mathrm{~ns}$ & & \\
\hline \multirow[t]{2}{*}{ Number of fruits } & 2001 & $0.96^{\star * *}$ & & & \\
\hline & 2002 & $0.91^{\star * \star}$ & & & \\
\hline
\end{tabular}

ns, not significant; ${ }^{* * *} \mathrm{P} \leq 0.001$. 
found in high concentrations in ovary walls have deterred feeding by, and were toxic to, Utetheisa ornatrix caterpillars (Gronquist et al., 2001).

Phenological differences were not examined in this study, but may also influence the relationship between plant bug damage and plant productivity; a field study with six cultivars found that the proportion of damaged fruits decreased with increasing number of fruits for early strawberry cultivars, but not for late cultivars (Rhainds \& English-Loeb, 2003a). As our damage severity score was highly correlated with the percentage of damaged fruits, we shall only use the percentage of damaged fruits in further studies. However, it is still worthwhile rating the fruits for damage, as it will ensure that observers look carefully for slightly damaged fruits.

Our emphasis was to identify resistance in dayneutral genotypes, because damage by tarnished plant bug is, arguably, the single most important deterrent to the rapid expansion of dayneutral cultivars in North America. In the dayneutral genotypes examined in this study, there was a range of resistance that could be used in breeding. 'Fort Laramie' consistently had less damage and can be considered as a source for resistance. 'Fort Laramie' has also been shown to transmit heat tolerance to its progeny (JF Hancock, pers. comm.). 'Tristar' had low damage in 2002, which confirms earlier findings (A Dale, unpubl). Several of the dayneutral $F$. virginiana genotypes had significantly less damage than 'Fort Laramie', but more generations of breeding will be needed to introduce this source into acceptable cultivars.

This work indicates that it should be possible to exploit the variability found to breed strawberry cultivars resistant to tarnished plant bugs. However, breeding programmes are typically conducted in fields where many different genotypes are present. How the tarnished plant bugs will react when potentially resistant cultivars are grown in monoculture is not known.

\section{Acknowledgements}

The authors wish to acknowledge the assistance of Skye Campbell. Funding was provided in part by the Ontario Berry Growers' Association, the Ontario Ministry of Agriculture and Food's (OMAF) Special Research Program, and the OMAF - University of Guelph Plants Program.

\section{References}

Anonymous (1997) The Brooks and Olmo Register of Fruit and Nut Varieties. ASHS Press, Alexandria, VA, USA.

Bostanian N (1994) The Tarnished Plant Bug and Strawberry Production. Agriculture Canada Research Branch Technical Bulletin 1994-1E. St. Jean-sur-Richelieu, QC, Canada.
Bringhurst RS \& Voth V (1980) Six new strawberry varieties released. California Agriculture 34: 12-15.

Brown M (2004) Trap crops show potential to reduce pest damage, save time and energy in organic strawberry production. The Cultivar 22: 1-3,17,18.

Dale A, Galic D \& Hallett R (2003) Fragaria virginiana tolerates tarnished plant bug. Hortscience 38: 687 (Abstract).

Dale A, Walker J \& Fisher P (2000) Growing Strawberries in Ontario. Publ.513. Ontario Ministry of Agriculture, Food and Rural Affairs, Toronto, ON, Canada.

Draper AD, Galletta GJ \& Swartz HJ (1981) 'Tribute' and 'Tristar' everbearing strawberries. Hortscience 16: 794-795.

Easterbrook MA \& Simpson DW (2000) Susceptibility of everbearing cultivars of strawberry to the European tarnished plant bug, Lygus rugulipennis. The Journal of Horticultural Science and Biotechnology 75: 405-408.

Easterbrook MA \& Tooley JA (1999) Assessment of trap plants to regulate numbers of the European tarnished plant bug, Lygus rugulipennis, on late-season strawberries. Entomologia Experimentalis et Applicata 92: 119-125.

Gronquist M, Bezzerides A, Attygalle A, Meinwald J, Eisner M \& Eisner T (2001) Attractive and defensive functions of the ultraviolet pigments of a flower (Hypericum calycinum). Proceedings of the National Academy of Sciences of the United States of America 98: 13745-13750.

Handley DT, Dill JF \& Pollard JE (1991) Field susceptibility of twenty strawberry cultivars to tarnished plant bug injury. Fruit Varieties Journal 45: 166-169.

Handley DT \& Pollard JE (1993) Microscopic examination of tarnished plant bug (Heteroptera: Miridae) feeding damage to strawberry. Journal of Economic Entomology 86: 505-510.

Handley DT, Schupp MA, Dill JF \& McCue JJ (1996) Strawberry variety performance and susceptibility to tarnished plant bug. Proceedings of the IV North American Strawberry Conference (ed. by MP Pritts, CK Chandler \& TE Crocker), pp. 222-224. Horticultural Sciences Department, University of Florida, Gainesville, FL, USA.

Kogan M \& Ortman EE (1987) Antixenosis - a new term proposed to replace Painter's 'non-preference' modality of resistance. Bulletin of the Entomological Society of America 24: 175-176.

Mass J (ed.) (1984) Compendium of strawberry diseases. American Phytopathological Society, St. Paul, MN, USA.

Okie WR (1999) Register of fruit and nut varieties, List 39. Hortscience 34: 181-205.

Ontario Ministry of Agriculture and Food (2001) Fruit Production Recommendations, Publication no. 362. The Queen's Printer, Toronto, ON, Canada.

Painter RH (1951) Insect Resistance in Crop Plants. Macmillan, New York, NY, USA.

Pritts M \& Dale A (1989) Dayneutral Production Guide. Cornell University Extension Information Bulletin 215, Ithaca, NY, USA.

Rancourt B, Vincent C \& de Oliveira D (2003) Field evaluation of efficacy and persistence of an insect vacuum device against the tarnished plant bug (Hemiptera: Miridae) in a day-neutral strawberry field. Journal of Economic Entomology 96: 401406. 
Rhainds M \& English-Loeb G (2003a) Variation in abundance and feeding impact of tarnished plant bug (Hemiptera: Miridae) for different cultivars of strawberry: role of flowering phenology and yield attributes. Journal of Economic Entomology 96: 433-440.

Rhainds M \& English-Loeb G (2003b) Testing the resource concentration hypothesis with tarnished plant bug on strawberry: density of hosts and patch size influence the interaction between abundance of nymphs and incidence of damage. Ecological Entomology 28: 348-358.

Rhainds M, Kovach J, Dosa EL \& English-Loeb G (2001) Impact of reflective mulch on yield of strawberry plants and incidence of damage by tarnished plant bug (Heteroptera: Miridae). Journal of Economic Entomology 94: 1477-1484.
Schaefers GA (1980) Yield effects of tarnished plant bug feeding on June-bearing strawberry varieties in New York State. Journal of Economic Entomology 73: 721-725.

Tilmon KJ \& Hoffmann MP (2003) Biological control of Lygus lineolaris by Peristenus spp. in strawberry. Biological Control 26: 287-292.

Udayagiri S, Welter SC \& Norton AP (2000) Biological control of Lygus hesperus with inundative releases of Anaphes iole in a high cash value crop. Southwestern Entomologist Suppl. 23: 27-38.

Vincent C \& Lachance P (1993) Evaluation of a tractor-propelled vacuum device for the management of tarnished plant bug populations in strawberry plantations. Environmental Entomology 22: 1103-1107. 